\title{
The effect of compound feed on the productivity of broiler chickens
}

\author{
Inna Korsheva, Elena Chaunina \\ Omsk State Agrarian University named after P.A. Stolypin, 1, Institute Square, Omsk, 644008, Russia
}

\begin{abstract}
The article analyses the issues of balanced feeding of broiler chickens and their balanced diet. The results of studies aimed to determine the effect of mixed feeds on the productivity of Arbor Acres cross broiler chickens and the economic efficiency of poultry meat production companies are presented. It was found that broilers from the experimental group, who were fed with improved compound feed with additional sources of proteins and carbohydrates and feed additives exceeded broilers from the control group by their live weight at all ages. At the slaughter age, the average weight was more than $39.2 \%$. The experimental group consumed 10-15\% less feed whose conversion was 2.4 and $1.9 \mathrm{~kg}$ in favour of the group feeding with the new compound feed. The new compound feed had a positive effect on the viability of broilers: there were no deaths during the period under study. According to the control slaughter results, it was found that the pre-slaughter live weight was higher by $35 \%$ in the experimental group. The weight of edible parts increased by $6 \%$. The improved compound feed can be used both in industrial conditions and by poultry farms.
\end{abstract}

\section{Introduction}

Livestock, being the main branch of the agricultural industry, determines the state of the domestic market, the level of consumption of high-grade food products and food security [1].

The volume of production of livestock products, including poultry, should be increased by feeding birds with high-quality feed $[2,3]$.

The high-quality forage base is a prerequisite for the successful development of husbandry. The most rational feeding provides animals with nutrients with the least labour and funds for forage production and requires a minimum forage area per a livestock product. The production of compound feed products meets all these requirements and is crucial in the feed base structure. Compound feed is a fully balanced product that contains vitamins, trace elements and other biologically active substances that ensure the healthy development of animals and poultry [4, 5]. The production of highquality compound feed is one of the most important parts of the food production chain from the field to the consumer, where food safety is ensured by the combined efforts of all participants in the production and consumption chain. The more productive feed is used, the higher the productivity. When using mixed feed balanced in all nutrients, the productivity increases by $10-12 \%$, and when using feed enriched with vitamins, microelements and other stimulating substances, it increases by $25-30 \%$ [3].

It is possible to replenish the lack of energy in the diet introducing 3-5\% of fodder fats (vegetable oil), stabilized by antioxidants into it.
For the intensive growth and normal development of broilers, mineral nutrition is extremely important. Such elements as chalk, fish and bone meal, defluorinated phosphates and kitchen salt should be introduced used in order to balance compound feeds in terms of minerals.

In order to improve metabolism and increase the use of energy and protein in broiler diets, it is necessary to introduce a complex of biologically active substances in the form of premixes.

The use of enzyme agents in poultry feed has long been a characteristic feature of modern industrial poultry farming. In the body of birds, enzymes are produced breaking down almost all components of feed - starch, sugar, fats and proteins. However, in the digestive tract of poultry, there are no synthesized enzymes helping in the digestion of fiber. This reduces the digestibility of feed nutrients and the efficiency of the enzyme system of birds. Therefore, additional enzyme preparations should be included in the compound feed. Nowadays many manufacturers offer ready-made feeds with enzyme additives, most of which are enzymes that destroy nonstarch polysaccharides of the grain cell wall: cellulases, hemicellulases and amylases. The use of exogenous enzymes is a very important additive for the improvement of feed digestibility. They reduce environmental pollution and dietary costs and improve poultry health and manure quality, which in turn have a positive effect on overall production costs.

However, it is necessary to take into account that enzymes have a narrow specificity and selectivity of action on substrates. They act only on one substance or substrate, as well as on a group of related substrates. Therefore, the choice of enzyme depends on the composition of the feed - the appropriate enzyme is

\footnotetext{
* Corresponding author: ia.korsheva@omgau.org
} 
selected for each type of diet. Correctly selected enzyme composition allows the use of available, cheap sources of raw materials, without harm to health and productivity of poultry and achievement of improvements in production and economic indicators.

Many authors speak about the effectiveness of feeding broilers with diets containing whole wheat grains, which has a positive effect on protein digestibility, poultry productivity and feed and protein consumption for weight gain and slaughter yield [2].

In the context of the change in the economic situation in the world, today compound feeds from the cheapest, but at the same time, difficult to digest components are used everywhere. These components are as follows barley, sunflower meal and seed cake, bran, meat and feather meal and others.

The use of a small amount of animal feed (up to 2\%) into diet as well as the balance of lysine and methionine increase the availability of these amino acids due to synthetic preparations.

However, in modern poultry farming there is a tendency to refuse to use feed of animal origin in poultry rations, due to their high cost and low quality. Having almost eliminated the use of expensive animal feed in poultry diets, poultry producers faced the dilemma of replacing animal feed with plant feed rich in proteins and essential amino acids. Today this problem is being solved through the increase of the introduction of soybean meal and other soybean derivatives. However almost all soybeans are grown from genetically modified sources.

The global community is in search of cheap unconventional feed products that would not be inferior in biological value to expensive protein feeds of animal and plant origin and could replace a part of the grain in the diet for the consumption of which poultry competes with humans [6-11]. One of the main tasks in the development of the poultry industry is the use of food industry waste and local non-traditional feed, as one of the ways to reduce production costs.

Non-traditional feed elements include rapeseed, lupine, peas, products of microbiological synthesis and fat and oil production, waste from the processing of livestock products (meat and bone meal, meat, eat and feathers of keratin and leather waste), as well as dry post-alcohol stillage, brewer's grains and others.

The environmental requirements and the development of industrial processing lead to a wider use in the practice of poultry feeding of unconventional feeds obtained from poultry evisceration waste through the introduction of enzymatic hydrolysis technology.

The changes in economic conditions at poultry farms require more rational use of fats and oils for energy nutrition of poultry and search for new types of energy feed, since the cost of fats and vegetable oils is very high. Therefore, farmers are looking for new sources of energy feed.

A good source of energy and essential fatty acids are feed phosphatides or waste sludge from vegetable oils. Enriching the main diet of poultry with these fat additives will undoubtedly have a positive effect on the productive qualities of the fattened poultry.
According to the studies this replacement does not entail negative consequences and has a beneficial effect on the productive qualities of poultry, its safety and also revises the prevailing opinion on the rational use of plant feed, not only as the main components, but also as a means of promoting better absorption of nutrient substances by poultry [3].

Moreover for modern poultry farming, a promising direction is the use of probiotics, prebiotics, symbiotics and other natural stimulators of poultry growth in the process of growing broiler poultry, with a complete refusal from feed antibiotics in order to obtain environmentally friendly products. In addition, the use of extracts of a number of plants, organic acids and other additives of natural origin is extremely important.

\section{Problem statement}

The high efficiency of broiler poultry farming is due to the high genetic potential of poultry which can be implemented only under the adequate feeding. It is crucial to provide the poultry farming with high quality and inexpensive feed. The used of mixed fodders made of cheaper local raw materials is most preferable, as it increases the efficiency of meat production [7, 10]. Broiler chickens have a high growth rate, are able to increase their body weight in a short time. In this regard, they must be fed with compound feeds balanced in all nutrients, minerals and biologically active substances. Thus, it is necessary to produce high-quality compound feed and assess its functional properties.

\section{Research Questions}

The study aims to determine the consumption of feed and their impact on the viability of broiler chickens; to establish the effect of compound feed on the dynamics of live weight and meat productivity; to determine the economic efficiency of feeding broiler chickens with mixed feeds.

\section{Purpose of the Study}

The purpose of the article is to describe experimental data on the efficient use of improved feed for broiler chickens.

\section{Research Methods}

The experiment was conducted on Arbor Acres cross broiler chickens aged 1-42 days. The experimental groups included broilers aged one day. The group method was used; the broilers were selected by the principle of analogues (by origin, age, physiological state and live weight). The groups included 40 broiler chickens. During the experiment, there was no separation by. The conditions in the groups were identical; the same staff observed the birds. 
The broilers of the experimental groups were divided into two ages: - 1-28 days and 29-42 days. The chickens were fed with balanced complete feed. The nutritional value of the compound feed was similar and corresponded to the age, but the composition was different. The second group received an improved compound feed with fodder corn, sunflower meal and meat and bone meal instead of fish meal. Sodium sulfate was additionally used from mineral additives.

In addition to the main ingredients, the compound feed used for the second group included several types of enzyme preparations - Agroxil, Rovabio XL and Sunfise 5000; antioxidants Agidol; adsorbent of mycotoxins with hepatoprotective action Fungistat.

The compound feed for the first group included Rovabio Max AR and Natufos 10000.

The chickens were weighted each week, the mortality was recorded and its causes were identified, the amount of feed eaten was recorded. At the end of the feeding period, selective slaughter and anatomical cutting of carcasses (three males and three females from each group) were carried out in order to determine the meat quality. The pre-slaughter weight was determined 12 hours after the last feeding; the slaughter weight is the weight of a poultry carcass without blood, plumage, intestines with cloaca, goiter and oviduct; the slaughter yield is the weight of a gutted carcass from the preslaughter weight in $\%$.

\section{Findings}

When feeding broiler chickens, the safety is an important indicator affecting the economic efficiency of meat production. In addition, it is the most important indicator of the physiological state and one of the main health indicators. In the first experimental group, during the first two weeks, the safety of was $100 \%$; during the third and fifth weeks, one death was recorded. There were no deaths in the second experimental group for the entire feeding period. The safety of livestock in the first group was $95.0 \%$, which is $5.0 \%$ less than in the second one.

The chickens were weighed; then they were divided into two similar groups. The live weight of broiler chickens was identical (Table 01) and amounted to 51.2$51.5 \mathrm{~g}$; however, there were differences in the dynamics. At all ages, chickens from the second experimental group were superior to those of the first experimental group. At the age of 7 days, the difference was $0.3 \mathrm{~g}$, or $0.5 \%$; at the age of 14 days, it was $8.5 \mathrm{~g}$, or $4.6 \%$; at the age of 21 days $-170.6 \mathrm{~g}$, or $26.6 \%$; at the age of 28 days - $258.4 \mathrm{~g}$, or $25.8 \%$; at the age of 35 -day $-497.6 \mathrm{~g}$, or $38.1 \%$. At the end of the feeding period, the chickens of the second experimental group exceeded the chickens of the first one by $676.0 \mathrm{~g}$, or $39.2 \%$. Since the age of 14 days, the difference was statistically significant, which makes it possible to exclude the random nature of the phenomenon.
Table 1. The dynamics of live weight of broiler chickens in the experimental groups $(\mathrm{g})$

\begin{tabular}{|c|c|c|}
\hline Age, days & Group 1 & Group 2 \\
\hline 1 & 51,2 & 51,5 \\
\hline 7 & 186,4 & 195,0 \\
\hline 14 & 403,1 & 463,8 \\
\hline 21 & 640,5 & 811,1 \\
\hline 28 & 998,9 & 1257,4 \\
\hline 35 & 1304,7 & 1802,4 \\
\hline 42 & 1724,9 & 2400,9 \\
\hline
\end{tabular}

At all ages, chickens of the second group exceeded chickens of the first one in an average daily gain of weight. In the initial period, the difference increased with aging: during the first, second and third weeks, it was $6.3 \%, 23.9 \%$ and $46.3 \%$, respectively. During the last week, the second group exceeded the first one by $44.1 \%$. In general, for 42 days, the average daily gain in the second group was $55.9 \mathrm{~g}$, which is $16.1 \mathrm{~g}$, or $40.4 \%$ more than in the first experimental group, where this indicator was $39.8 \mathrm{~g}$

The hematological parameters are important for assessing the physiological status of the body. There is a direct relationship between these parameters and the growth rate [12]. The hemoglobin content, the number of erythrocytes and leukocytes in broiler chickens were within the physiological norm. At the same time, at all ages in the blood of chickens of the first group, the number of erythrocytes was less than in the second group by $15.9 \%$. Since the age of 14 days, the number of leukocytes in the second experimental group was larger than in the first one by $0.39-5.41 \%$, which indicates an increase in the activity of the hematopoietic apparatus due to the intensive growth of broiler chickens. The hemoglobin content tended to increase with aging. Blood in the second group was highly saturated with hemoglobin at all ages.

In the first group, the content of albumin was higher, and the content of globulins was slightly less. a significant difference in the content of albumin was established only at the age of 42 days (10.9\%). Feed consumption is one of the main factors affecting the productivity. At all ages except for the age of 8-14 days, broiler chickens of the second group consumed 3.9$20.8 \%$ more feed than chickens of the first group. On average, for 42 days, the average daily consumption of the improved feed was more by $9 \mathrm{~g}$, or $8.9 \%$ per head.

The index indicator characterizing the ratio of the growth rate to feed consumption is the feed consumption for live weight gain [13]. Due to the higher feed consumption and lower live weight gain, the feed costs per $1 \mathrm{~kg}$ of gain in the first group were higher than in the second one by $0.27 \mathrm{~kg}$ at the age of $1-28$ days, and by $0.77 \mathrm{~kg}$ at the age of $29-42$ days. The results of calculating the conversion of compound feed, taking into account the live weight, showed that in the experimental 
group it was $2.37 \mathrm{~kg}$, which is $18.6 \%$ more than in the second group.

Thus, it was found that broiler chickens of the second group, which received the improved compound feed, used the nutrients more efficiently.

The relationship between the live weight and mortality [14] has been identified. According to the control slaughter results (Table 02), the pre-slaughter weight was higher in the second group - by $647 \mathrm{~g}$ $(35.7 \%)$. The weight of half-gutted carcasses in the second group also exceeded the one in the first one by $581 \mathrm{~g}(37.0 \%)$.

Table 2. Meat productivity for broiler chickens

\begin{tabular}{|c|c|c|}
\hline Parameter & Group 1 & Group 2 \\
\hline Pre-slaughter live weight, g & 1812,3 & 2459,1 \\
\hline Slaughter weight, g & 1690,4 & 2293,7 \\
\hline Half-gutted carcass weight, g & 1570,1 & 2151,4 \\
\hline Semi-gutted carcass weight, g & 86,6 & 87,5 \\
\hline Gutted carcass weight, g & 1246,6 & 1702,7 \\
\hline Slaughter weight, \% & 68,8 & 69,2 \\
\hline Weight of edible parts, g & 1204,8 & 1639,4 \\
\hline $\begin{array}{c}\text { Mass of inedible parts, g } \\
\text { The ratio of edible parts to } \\
\text { inedible parts }\end{array}$ & $2,503,7$ & 654,4 \\
\hline
\end{tabular}

The slaughter yield in all groups was high - about $69 \%$. Due to the greater weight of gutted carcasses (by $456 \mathrm{~g}$, or $36.6 \%$ ), in the second group, an increase in the slaughter yield was $0.4 \%$.

The anatomical cutting of chicken carcasses showed that the weight of edible parts in the second experimental group was larger than in the first one by $434 \mathrm{~g} \mathrm{(36.1 \% ).}$ At the same time, the ratio of edible to inedible parts was 0.3 higher in the second group.

The characteristics and quality of meat depend on the intensity of growth [15]. In terms of the chemical composition of meat, the groups had significant differences. The males of the first group exceeded the one in the second one by the moisture content, but were inferior by the content of dry matter, fat and ash (by $0.36 \%, 0.08 \%$, and $0.01 \%$, respectively). Females of the first group exceeded the second group by the dry matter content by $0.53 \%$, ash - by $0.06 \%$, while being inferior by the moisture and fat content by $0.11 \%$. On average, meat of broiler chickens of the first group contained $0.09 \%$ and $0.06 \%$ more dry matter and ash. The second group exceeded the first one in terms of the moisture and fat content by $0.09 \%$ and $0.1 \%$, respectively.

\section{Conclusion}

The cost of feed consumed by the second experimental group was $44.4 \%$ higher than the cost of feed consumed by the first group. But due to higher productivity and higher revenues, the profit in the second group was $31.4 \%$ higher. As a result, the profitability in the second experimental group exceeded the one in the first one by $11.2 \%$.

\section{Acknowledgments}

The authors express gratitude for the technical support provided by the center for collective use of scientific equipment "Agrarian and Technological Research" of Omsk SAU.

\section{References}

1. E. Chaunina, I. Korsheva, Handbook of Research on Globalized Agricultural Trade and New Challenges for Food Security (IGI Global, Hershey, 2020)

2. Q. Berger, E. Guettier, S. Urvoix, J. Bernard, P. Ganier, M. Chahnamian, E. Le Bihan-Duval, S. Mignon-Grasteau, Poult. Sci., 100(4), 101010 (2021)

3. I. Plavnik, B. Macovsky, D. Sklan, Anim. Feed Sci. Technol., 96 (3-4), 229-236 (2002)

4. Van der Klis J. D., A. J. M. Jansman, J. Anim. Sci., 28 (3), 499-505 (2019)

5. P. Jiao, Y. Guo, X. Yang, F. Long, J. Anim. Vet. Adv., 9 (11), 1546-1551 (2010)

6. M. Toghyani, S.B. Wu, R.A. Pérez-Maldonado, P.A. Iji, R.A. Swick, Poult. Sci., 96 (11), 39603972 (2017)

7. H. N. Moghaddam, S. Salari, J. A. V. D. Arshami, A. Golian, M. O. H. S. E. N. Maleki, J. Appl. Poult. Res., 21(2), 293-304 (2012)

8. M. Foltyn, V. Rada, M. Lichovníková, E. Dračková, Acta Univ. Agric. Silvic. Mendelianae Brun., 61(1), 59-64 (2013)

9. D. Diaz, M. Morlacchini, F. Masoero, M. Moschini, G. Fusconi, G. Piva, It. J. Anim. Sci., 5(1), 43-53 (2006)

10. M. Alagawany, A. I. Attia, Z. A. Ibrahim, R. A. Mahmoud, S. A. El-Sayed, Env. Sci. Poll. Res. Int., 24(13), 12319-12327 (2017)

11. E. Gopinger, E. G. Xavier, M. C. Elias, A. A. S. Catalan, M. L. S. Castro, A. P. Nunes, V. F. B. Roll, Poult. Sci., 93(5), 1130-1136 (2014)

12. C. G.s Scane, Blood. Sturkie's Avian Physiology (Elsevier Inc., London, 2015)

13. J. A. Howie, B. J. Tolkamp, S. Avendano, I. Kyriazakis, Poult. Sci., 88(6), 1143-1150 (2009)

14. M. Mendes, E. Akkartal, Arch Geflügelk, 71, 267271 (2007)

15. E. Le Bihan-Duval, M. Debut, C. M. Berri, N. Sellier, V. Santé-Lhoutellier, Y. Jégo, C. Beaumont, BMC Genet., 9(1), 1-6 (2008) 